\title{
ESTUDO SOBRE OS TIPOS DAS ÁGUAS E AS CONDICIONANTES ESTRUTURAIS DO SISTEMA AQÜÍFERO GUARANI NO EXTREMO OESTE DO ESTADO DO PARANÁ
}

\author{
GROUNDWATER TYPES AND STRUCTURAL CONDITIONING STUDY \\ OF THE GUARANI AGUIFER SISTEM IN THE WESTERN OF PARANÁ STATE (BRAZIL)
}

\author{
Ernani Francisco da Rosa Filho ${ }^{1}$, André Virmond Lima Bittencourt ${ }^{1}$, \\ Eduardo Chemas Hindi ${ }^{1}$ e Alexander Bittencourt ${ }^{2}$
}

Recebido em: 05/07/2006; aceito em: 10/11/2006

\begin{abstract}
RESUMO No presente trabalho é apresentada a tipologia das águas do Sistema Aqüífero Guarani (SAG), em especial, e do Sistema Aqüífero Serra Geral (SASG), bem como sobre a estruturação tectônica que afeta os dois aquíferos mencionados, na área de abrangência da bacia hidrográfica do Paraná 3 que está localizada no extremo oeste do Estado do Paraná. O SAG encontra-se confinado, com mais de $600 \mathrm{~m}$ de basaltos sobre ele. As suas águas são sulfatadas ou cloretadas, com teores de sólidos totais dissolvidos (STD) acima de $1.000 \mathrm{mg} . \mathrm{L}^{-1}$ e com predominância do íon sódio sobre o cálcio e o magnésio. As águas do SASG que sofrem forte influência do SAG, mesmo com perfurações seccionando apenas $180 \mathrm{~m}$ de basaltos, são mistas e similares em todos os aspectos físico-químicos com as águas do SAG, inclusive com temperatura superior a $30^{\circ} \mathrm{C}$. Ainda que as águas do SAG estejam sendo destinadas, na região, para fins turísticos, elas também podem ser usadas para abastecimento público, desde que diluídas em proporções adequadas com águas superficiais. Esta diluição foi feita por meio de uma simulação com o programa computacional PHREEQEC. O intenso sistema de falhamentos geológicos na região, predominantemente com direções SE-NW, representam zonas de descarga do SAG, inclusive recarregando o SASG. O SAG é composto por vários compartimentos hidrogeológicos causados por esses falhamentos geológicos e por intrusões de diques de diabásio, sendo que cada um deles possui uma dimensão própria. Em razão da complexidade desses sistemas aqüíferos em termos da sua distribuição no espaço, da elevada altura da carga hidráulica de cada compartimento hidrogeológico e da idade da água, acima de 20.000 anos, ainda não existem dados científicos para uma compreensão sobre os processos de recarga do SAG na região.
\end{abstract}

Palavras-Chave - Água subterrânea; Sistema Aqüífero Guaraní; hidroquímica.

\begin{abstract}
The hydrochemical typology and the tectonic structures that affect the Guarani Aquifer System (GAS) and Serra Geral Aquifer System (SGAS) in in the western part of Paraná Sedimentary Basin, in Paraná State (Brazil), are discussed in this work. The SAG is placed $600 \mathrm{~m}$ under the Mesozoic basalt and other volcanic-related rock layers. The aquifer waters are sulfated and chlorinated, with a total dissolved solids ratio higher than $1.000 \mathrm{mg} \mathrm{L}^{-1}$ with a particular predominance of sodium ions in relation to calcium as well as magnesium. Even though SASG drills may reach less than $180 \mathrm{~m}$ into the basaltic rock layers, this aquifer system show similar hydrochemical and physicochemical characteristics with to SAG waters including temperatures above $30^{\circ} \mathrm{C}$. Although the SAG waters are currently being used for tourism purposes, when appropriately mixed with proper amount of surface waters it can be used as drinking water supply. The high density of geologic faults in the region, mainly in the SE-NW direction, acts as GAS discharge zones and eventually, recharging upwards the SGAS. The GAS hydrogeological framework can be represented by a series of compartments which are resultant from the geologic faults and intrusions of dolerite dykes. The recharge process is not completely understood for this part of the GAS, due to its structural complexity. Isotopic analysis from water samples collected in the study area result that the GAS water age are over 20,000 years.
\end{abstract}

Keywords: groundwater, Guarani Aquifer System, hydrochemistry.

\section{INTRODUÇÃO}

Tem sido freqüentemente reportado pela mídia que as águas armazenadas no Sistema Aquífero Guarani (SAG) representam a grande solução para o abastecimento das populações que habitam nas regiões onde ele ocorre. Esta população corresponde a aproximadamente 29 milhões de pessoas. Esse tipo de divulgação, feita de forma sensacionalista ao longo dos últimos anos, criou expectativas irreais, fora do contexto da relação entre a qualidade da água armazenada neste aquíf́ero e a demanda, atual e futura, em grande parte de sua área de ocorrência
Estudos publicados nos últimos anos (ROSAFILHO; SALAMUNI; BITTENCOURT, 1987; ROSA FILHO et al., 2000; BITTENCOURT et. al., 2003; SOUZA, 2004; BORGHETI; BORGHETI; ROSA FILHO, 2004; ROSA FILHO et al., 2005, ROSA FILHO et al., 2006; HINDI, 2007) permitem constatar que, pelo menos no Estado do Paraná, em mais do que $50 \%$ de sua área de ocorrência predominam águas que não são adequadas ao consumo humano, na sua condição in natura. Essas áreas estão situadas na região central, oeste e sudoeste do Paraná, onde, via de regra, existe

\footnotetext{
${ }^{1}$ Laboratório de Pesquisas Hidrogeológicas (LPH) - Departamento de Geologia UFPR (ernani@ufpr.br), (andré@ufpr.br) $e$ (hindi@ufpr.br)

${ }^{2}$ Curso de Pós-Graduação em Geologia, Departamento de Geologia UFPR (alexbitte@ yahoo.com.br)
} 
uma cobertura de basaltos com espessura superior a $600 \mathrm{~m}$. Uma proposta relevante, com relação ao aproveitamento das águas do SAG nessas regiões seria, em princípio, a diluição com águas superficiais de qualidade adequada.

Registre-se, por outro lado, que também existem situações nas quais essas águas se enquadram aos padrões de potabilidade, sendo que para essas situações as águas deste aqüífero já abastecem cerca de quarenta sistemas operados pela Companhia de Saneamento do Paraná (SANEPAR).

Tendo em conta a elevada temperatura de suas águas em regiões de alto grau de confinamento do SAG, elas podem ser aproveitadas para diversos usos, tal como descrito por Borghetti; Borghetti; Rosa Filho (2004).

\section{LOCALIZAÇÃO DA ÁREA DE ESTUDO}

A área de estudo localiza-se na Bacia Hidrográfica do Paraná III (Figura 1) no extremo oeste do Estado do Paraná, onde afloram rochas vulcânicas da Formação Serra Geral. O relevo varia de ondulado a suave ondulado, com altitudes entre 300 e $700 \mathrm{~m}$. Essa bacia é integrada pelos rios São Francisco Falso, Taturi, Ocoí, Chocoró, Arroio Fundo e São Vicente, sendo que todos eles deságuam no lago de Itaipu. A referida bacia tem área total de $8.389 \mathrm{~km}^{2}$, estando ocupada por uma população de 997.500 habitantes, distribuídas por 27 municípios.

\section{OBJETIVO}

O objetivo deste trabalho é caracterizar tipologia das águas do SAG e delinear as principais descontinuidades geológicas do SAG na área delimitada pela bacia hidrográfica do Paraná 3.

\section{CONSIDERAÇÕES SOBRE A GEOLOGIA GERAL}

As unidades geológicas que ocorrem na região, e que influenciam o desenvolvimento do presente estudo, são representadas pelas formações Pirambóia, Botucatu, ambas subjacentes à Formação Serra Geral, sendo que as idades das três unidades são atribuídas ao Triássico.

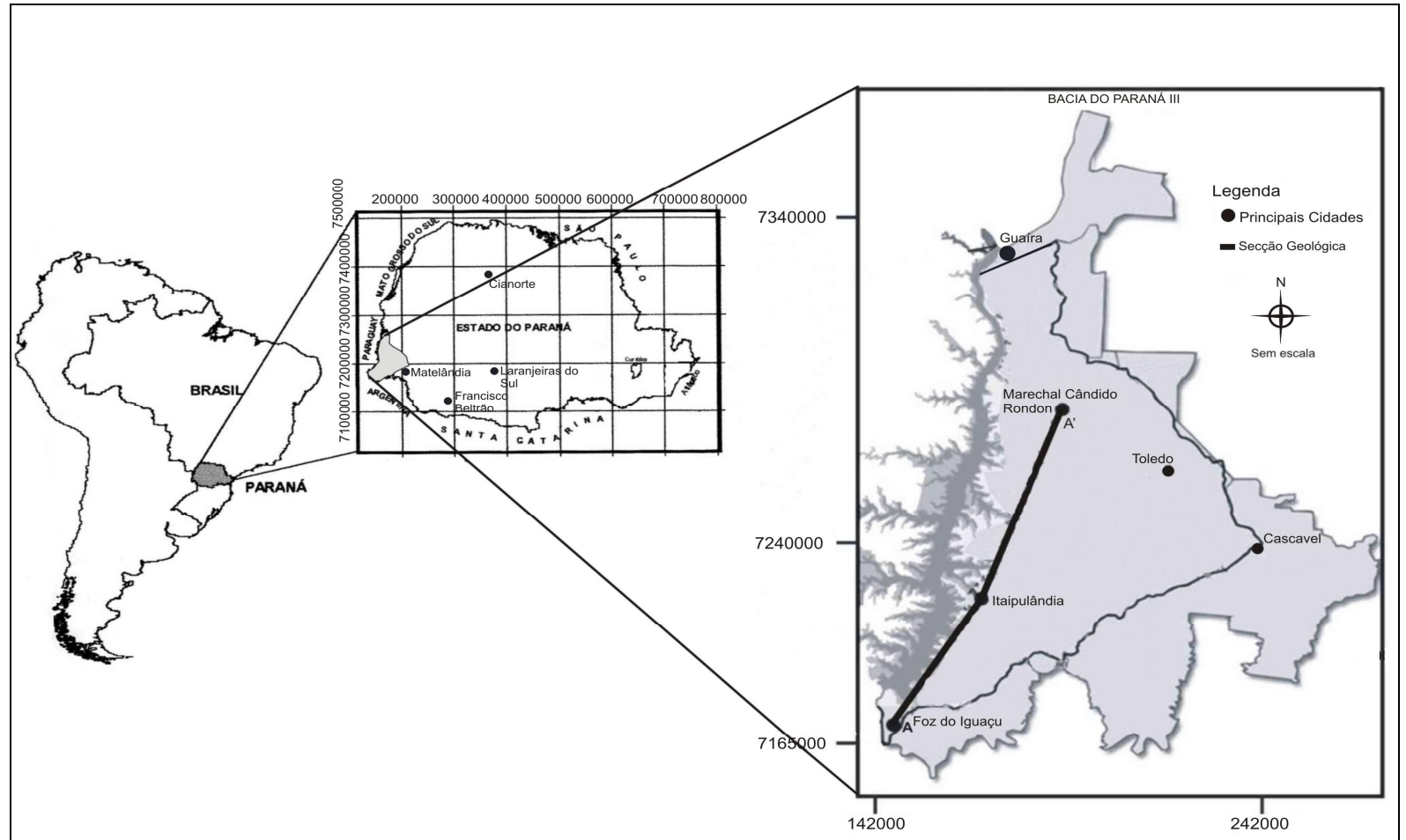

Figura 1- Localização da área de estudo indicando no detalhe, a linha A-A' correspondente à seção geológica apresentada na figura 2.

Figure 1-Study area location. In detail is shown the geological section line AA' presented on figure 2

Com relação aos arenitos da Formação Pirambóia, destaca-se o estudo de Pacheco (1927), proponente desta denominação, sendo que os estudos [TIPO?] mais recentes foram desenvolvidos por Mezzalira (1981), Paraguassu (1968), Soares (1975) e Caetano-Chang e Wu
(1992). No Estado do Paraná esta unidade é representada por arenitos de cor branca.

A Formação Botucatu foi originalmente definida por Campos (1899), que a designou como uma unidade constituída por arenitos vermelhos sobrepostos à Formação Pirambóia. 
Dentre os estudos sedimentológicos e estratigráficos, destacam-se os trabalhos elaborados por Mezzalira (1981), Soares (1973), Scheider et al. (1974), Soares (1975) e Caetano-Chang e Wu (1992). Esses sedimentos constituem o registro de deposição eólica em condições desérticas.

Os primeiros relatos científicos sobre as rochas vulcânicas da Formação Serra Geral, as quais são constituídas predominantemente por basaltos toleíticos, foram feitos por Derby (1878) e por White (1908). Destacam-se, igualmente, os trabalhos desenvolvidos por Gordon Jr. (1947), Leinz (1949), Ruegg (1975), Sartori e Maciel Filho (1976), Sartori e Gomes (1980), Piccirilo e Melfi (1988) e Chang e Kowsmann (1991).

\section{CARACTERIZAÇÃO HIDROGEOLÓGICA DA ÁREA ESTUDADA}

Na região da bacia do Paraná 3 afloram os basaltos do Sistema Aqüífero Serra Geral (SASG), cujas espessuras variam de 632 a $920 \mathrm{~m}$. $\mathrm{O}$ armazenamento e circulação da água subterrânea no SASG está, fundamentalmente, relacionado às descontinuidades geológicas como, falhas, diáclases, e superfícies interderrames, estas últimas têm sua capacidade de armazenamento aumentada pela ocorrência de zonas vesiculares.

Os arenitos subjacentes ao SASG constituem o Sistema Aquíffero Guarani (SAG). A espessura do conjunto de sedimentos na área de estudo, incluindo os arenitos das formações Pirambóia e Botucatu, varia de 70 a $125 \mathrm{~m}$.

As duas unidades aqüíferas foram afetadas pelo soerguimento do Arco de Ponta Grossa. A malha de falhamentos geológicos regionais resultantes desse processo causou a conectividade hidráulica entre o SASG e o SAG, tal como foi descrita por Portella Filho (2002) e por Strugale (2002), que usaram dados aeromagnetométricos, bem como por Souza (2004), Rosa Filho et. al., (2005) e Hindi (2007); estas três últimas citações estão baseadas em estudos geoestruturais, associados com análises de dados hidroquímicos.

Subjacentes aos reservatórios onde se encontram as águas armazenadas do SAG, ocorrem os sedimentos pelíticos da Formação Rio do Rasto, de idade Paleozóica Superior.

\section{Condicionantes geoestruturais}

Nas cidades de Foz do Iguaçu, Itaipulândia e Marechal Cândido Rondon, as altitudes do topo do SAG correspondem a $-357 \mathrm{~m},-631 \mathrm{~m} \mathrm{e}$ $375 \mathrm{~m}$, respectivamente. Entre a primeira e a segunda cidade, o deslocamento de blocos é da ordem de $274 \mathrm{~m}$ (a diferença de cota do terreno é de $85 \mathrm{~m}$ ), e entre a segunda e a terceira cidade, o deslocamento corresponde a $256 \mathrm{~m}$ (a diferença de cota do terreno é de $131 \mathrm{~m}$ ). Considerando a diferença entre a cota do terreno e o topo do SAG, o menor deslocamento de blocos entre Foz do Iguaçu e Itaipulândia, distantes $50 \mathrm{~km}$ entre si, é de $189 \mathrm{~m}$ e, entre Itaipulândia e Marechal Cândido Rondon, é de 125 m. Essas relações podem ser vistas na figura 2 .

As principais drenagens da região apresentam as mesmas direções das intrusões de diabásios, ou seja, NW-SE, tal como estão configurados os alinhamentos do rio Piquiri, do rio Alonso e São Jerônimo-Curiúva, descritos por Ferreira (1982a). As drenagens que estão encaixadas nesses alinhamentos são os rios Ocoí (cerca de $50 \mathrm{~km}$ de extensão), entre Foz do Iguaçu e Itaipulândia, e os rios São Francisco Falso (aproximadamente $75 \mathrm{~km}$ de extensão) e São Francisco Verdadeiro (aproximadamente 50 $\mathrm{km}$ de extensão), entre Itaipulândia e Marechal Rondon.

A seção geológica apresentada na figura 2 está disposta em direção quase perpendicular aos alinhamentos mencionados. Pressupõe-se, portanto que essas diferenças de cotas do topo do SAG entre os pontos onde foram perfurados os poços tenham sido causadas pelo soerguimento do Arco de Ponta Grossa, o que resultou numa malha de falhamentos geológicos regionais. Essa estruturação parece evidente na distribuição espacial das propriedades físicas e químicas conforme mostrado em Hindi (2007).

A secção geológica mostrada na figura 2 revela que na região de Itaipulândia, entre as cidades de Foz do Iguaçu e Marechal Rondon (distantes $48 \mathrm{~km}$ entre si), a cota do topo do SAG na sua parte mais profunda varia de -274 até $312 \mathrm{~m}$, sendo inferior às cotas do topo do SAG em Foz do Iguaçu e em Marechal Cândido Rondon. A conformação geométrica desta secção assemelha-se, sob o ponto de vista geomorfológico, a uma estrutura do tipo graben. Na tabela 1 são apresentados os dados relativos à cota do terreno, a profundidade total dos poços tubulares, as espessuras de basaltos e de arenitos seccionados nas perfurações. 
Tabela 1- Dados sobre a cota do terreno, profundidade dos poços e espessuras de basaltos e de arenitos de poços localizados dentro e fora da bacia do Paraná 3.

Table 1- Dados sobre a cota do terreno, profundidade dos poços e espessuras de basaltos e de arenitos de poços localizados dentro e fora da bacia do Paraná 3.

Poços localizados na área de abrangência da bacia hidrográfica do Paraná 3

\begin{tabular}{l|c|c|c|c}
\hline \multicolumn{1}{c|}{ Cidade } & $\begin{array}{c}\text { Cota do Poço } \\
(\mathbf{m})\end{array}$ & $\begin{array}{c}\text { Profundidade } \\
\text { Total (m) }\end{array}$ & $\begin{array}{c}\text { Espessura } \\
\text { Basalto (m) }\end{array}$ & $\begin{array}{c}\text { Espessura } \\
\text { Arenitos (m) }\end{array}$ \\
\hline Marechal Cândido Rondon & 420 & 920 & 795 & 125 \\
\hline Itaipulândia & 289 & 1030 & 920 & 110 \\
\hline Foz do Iguaçu - Poço 1 M.H. & 204 & 810 & 561 & 71 \\
\hline Foz do Iguaçu - Poço 2 B. H. & 218 & 632 & 540 & 92 \\
\hline
\end{tabular}

Poços localizados na parte externa da bacia hidrográfica do Paraná 3

\begin{tabular}{l|c|c|c|c}
\hline \multicolumn{1}{c|}{ Cidade } & $\begin{array}{c}\text { Cota do Poço } \\
(\mathbf{m})\end{array}$ & $\begin{array}{c}\text { Profundidade } \\
\text { Total (m) }\end{array}$ & $\begin{array}{c}\text { Espessura } \\
\text { Basalto (m) }\end{array}$ & $\begin{array}{c}\text { Espessura } \\
\text { Arenitos (m) }\end{array}$ \\
\hline Cianorte & 580 & 1564 & 1.402 & 127 \\
\hline Cascavel - Termas de Cascavel & 649 & 1.088 & 1.088 & - \\
\hline $\begin{array}{l}\text { Francisco Beltrão - Termas do } \\
\text { Sudoeste }\end{array}$ & 799 & 1.356 & 1.356 & - \\
\hline Laranjeiras do Sul - Petrobrás & 826 & 1.014 & 1.014 & - \\
\hline Matelândia & 345 & 908 & 908 & - \\
\hline
\end{tabular}

Condicionantes sobre o escoamento das águas no SAG

Com exceção dos poços localizados na área de abrangência da bacia hidrográfica do Paraná 3, os demais poços localizados em regiões próximas da área de estudo não seccionaram os arenitos que constituem o SAG.[??]

A diferença da potenciometria entre os poços de Foz do Iguaçu (poços do H.M. e do H.B.), distantes $600 \mathrm{~m}$ entre si, é de $4 \mathrm{~m}$. Destaque-se, neste caso, que a relação da altura da carga hidráulica em função da distância ente os dois poços, de $6,6 \mathrm{~m} / \mathrm{km}$, é conseqüência do alívio de pressão da água e da compressão dos basaltos sobre os arenitos, efeitos esses que ocorreram simultaneamente tão $\operatorname{logo}$ as perfurações atingiram o aqüífero, primeiramente através do poço do M.H. (produzindo água a mais de uma década), e posteriormente através do poço do H.B. (concluído no final do ano de 2006). A altura da carga hidráulica e as vazões de surgências desses poços ainda não estão em equilíbrio; a estabilização deverá ocorrer em função do tempo, com reduções da altura da carga hidráulica. Destaque-se que entre esses dois poços não foi constatada a existência de descontinuidades geológicas.

Os falhamentos geológicos com grandes deslocamentos de blocos, tal como mostrado na figura 2, são indicativos da existência de compartimentos hidrogeológicos, cada qual com sua carga hidráulica. Na região de Foz do Iguaçu, a altura da carga hidráulica é superior à cota do terreno, o que favorece o fenômeno do artesianismo. Nas localidades mencionadas na tabela 2, a água do SAG ascende por pressão e se mistura com as águas do SASG. Esse processo é bastante notado na cidade de Marechal Cândido Rondon, onde os poços com profundidades entre 150 e $200 \mathrm{~m}$, penetrantes apenas no SASG, apresentam tipos de águas com características químicas mistas. Os rios principais da bacia do Paraná 3, já mencionados, estão encaixados nas estruturas com direções SE-NW; é através dessas feições estruturais que ocorre a descarga das águas do SAG na região estudada.

Uma das questões ainda indefinidas em regiões onde o SAG encontra-se confinado por mais de $600 \mathrm{~m}$ de espessura de basaltos e sob elevada pressão hidráulica, o que força a elevação da água do SAG para o SASG, bem como em função da idade de suas águas, acima de 20.000 anos (ROSA FILHO et al. 2006), se refere aos processos de recarga do SAG.

Sob a hipótese de inexistência de recarga através da precipitação, ou de qualquer outra fonte, é admissível pressupor que o volume da água explotável do SAG, nessa região, seja finito. E sendo assim, a exploração sustentada para um determinado tempo exige, no mínimo, conhecimentos sobre as dimensões dos compartimentos hidrogeológicos e os respectivos volumes de águas armazenadas, sendo que o esgotamento de cada compartimento ("mineração da água") será, então, função da vazão extraída em relação ao regime de bombeamento. 
Tabela 2- Dados dos poços localizados na bacia hidrográfica do Paraná 3 que seccionaram o SAG Table 2- Dados dos poços localizados na bacia hidrográfica do Paraná 3 que seccionaram o SAG

\begin{tabular}{l|c|c|c|c|c|c}
\hline \multicolumn{1}{c}{ Cidade } & $\begin{array}{c}\text { Cota do } \\
\text { Poço }(\mathbf{m})\end{array}$ & $\begin{array}{c}\text { Nível } \\
\text { hidrostático } \\
(\mathbf{m})\end{array}$ & $\begin{array}{c}\text { Profundidade } \\
\text { Total do poço } \\
(\mathbf{m})\end{array}$ & $\begin{array}{c}\text { Cota do topo } \\
\text { do SAG }(\mathbf{m})\end{array}$ & $\begin{array}{c}\text { Altura da carga } \\
\text { hidráulica }(\mathbf{m})\end{array}$ & $\begin{array}{c}\text { Vazão } \\
\left(\mathbf{m}^{3} / \mathbf{h}\right)\end{array}$ \\
\hline Marechal Cândido Rondon & 420,0 & $-92,0$ & 920,0 & $-375,0$ & 328,0 & $90,0(\mathrm{a})$ \\
\hline Itaipulândia & 289,0 & $-10,0$ & $1.030,0$ & $-631,0$ & 279,0 & $75,0(\mathrm{a})$ \\
\hline Foz do Iguaçu - (H.M) & 204,0 & $+40,0$ & 810,0 & $-357,0$ & 244,0 & $82,0(*)$ \\
\hline Foz do Iguaçu - (H.B) & 218,0 & $+22,0$ & 632,0 & $-336,0$ & 240,0 & $41,0(*)$ \\
\hline
\end{tabular}

*Surgência natural; (a) Vazão de Teste

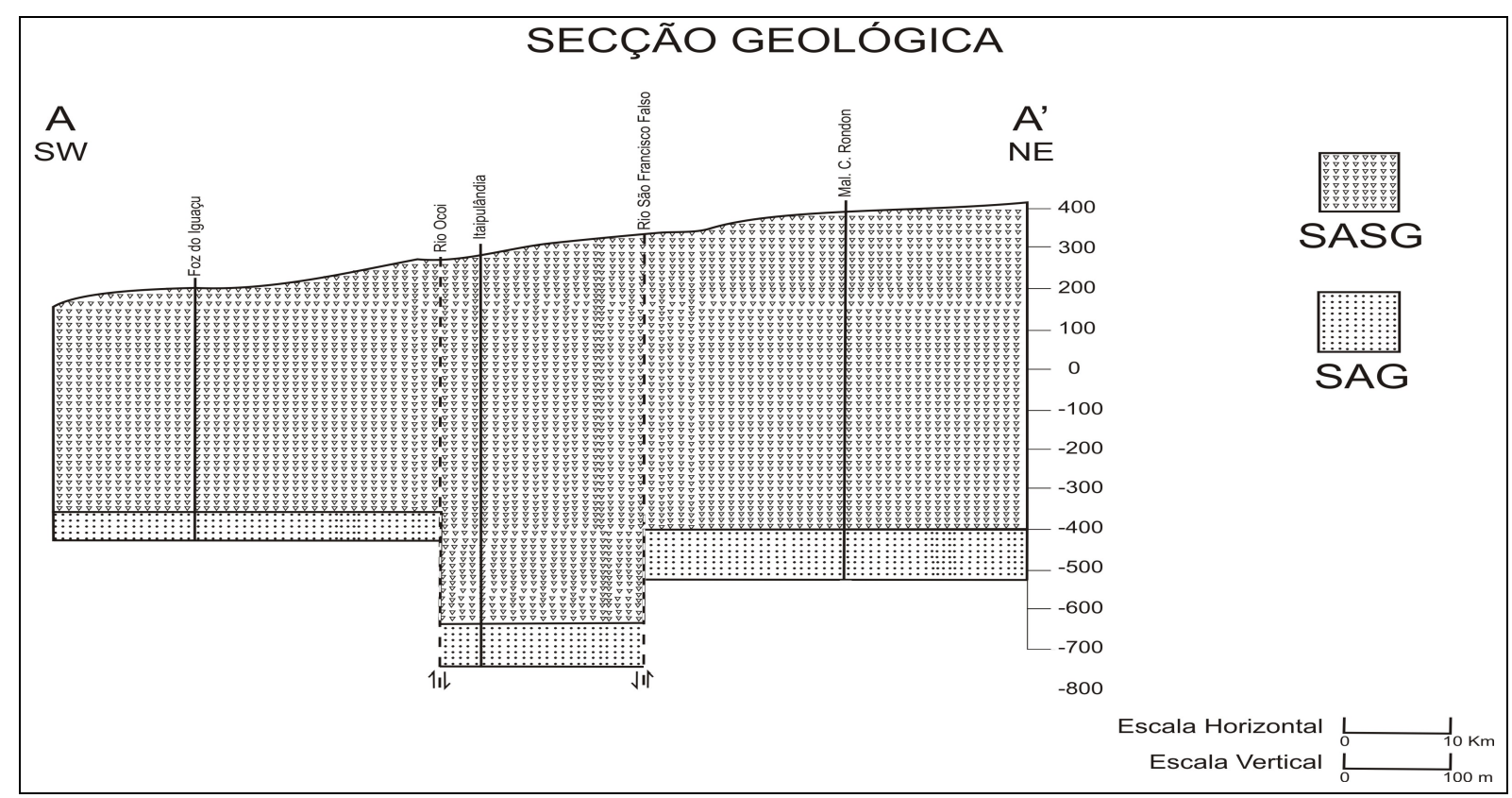

Figura 2- Secção geológica mostrando a existência de falhamentos geológicos no SAG e no SASG na região da bacia hidrográfica do Paraná 3 (subjacente ao SAG ocorrem as rochas pelíticas da Formação Rio do Rasto) Figure 2- Secção geológica mostrando a existência de falhamentos geológicos no SAG e no SASG na região da bacia hidrográfica do Paraná 3 (subjacente ao SAG ocorrem as rochas pelíticas da Formação Rio do Rasto)

Condicionantes sobre a tipologia das águas do SAG

A espessura de basaltos sobrepostos ao SAG na bacia do Paraná 3 varia de 540 a 920 m. Tratase de uma situação de alto grau de confinamento onde predominam águas sulfatadas ou cloretadas sódicas, a exemplo do que foi mencionado por Hindi (2007). Sob esta condição, predomina o sódio sobre o cálcio e o magnésio, a concentração de bicarbonato é inferior a de sulfato e de cloreto, as concentrações de fluoreto variam de 5,4 a 7,35 mg. $\mathrm{L}^{-1}$, sendo que os sólidos totais dissolvidos (STD) apresentam teores entre 1.650 a 2.208 mg. $\mathrm{L}^{-1}$, os valores do $\mathrm{pH}$ situam-se entre 8,14 a 8,70 e a temperatura da água atinge valores entre 38 a $41{ }^{\circ} \mathrm{C}$.

As águas coletadas nos poços penetrantes apenas no SASG, sem forte influência do SAG, são do tipo bicarbontadas cálcicas, onde os STD variam de 161 a $176 \mathrm{mg} . \mathrm{L}^{-1}$, predominando o cálcio sobre o sódio, sendo o pH máximo igual a 7,89 e o conteúdo de fluoreto é inferior a 0,1 mg. $\mathrm{L}^{-1}$. Esses poços apresentam profundidades inferiores a $180 \mathrm{~m}$, mas a temperatura da água, em vez de se situarem na faixa de 21 a $22{ }^{\circ} \mathrm{C}$, apresentam valores de até $28^{\circ} \mathrm{C}$; essas temperaturas mostram que existe uma influência, mesmo que não tão significativas, do SAG sobre o SASG, resultando numa água do tipo mista (Figura 3).

A influência mais nítida do SAG sobre o SASG ocorre nos poços igualmente penetrantes apenas no SASG, mas que apresentam STD entre 1.000 e $2.000 \mathrm{mg} . \mathrm{L}^{-1}$, com teores de cloreto e sulfato acima de bicarbonato, bem como com predominância do sódio sobre o cálcio. Nesses casos, os teores de fluoreto variam de 5 a $8 \mathrm{mg.L}{ }^{-}$ ${ }^{1}$, e a temperatura atinge $33^{\circ} \mathrm{C}$. As tipologias das águas do SASG, das águas misturadas e das águas típicas do SAG em condição de elevado confinamento, são mostradas na figura 3 e na tabela 3 .

Discutindo o quimismo de águas subterrâneas do Terceiro Planalto paranaense, Bittencourt (1978) imputa ao aqüífero Botucatu a origem de elevados teores em álcalis ascendendo por fraturas e captados por poços perfurados no SASG. 
O zoneamento hidroquímico das águas desses dois aquíferos na área de abrangência do Terceiro Planalto do Paraná, foi primeiramente descrito no trabalho de Rosa Filho, Salamuni; Bittencourt (1987). Segundo Rosa Filho et. al. (2005; 2006) e Hindi (2007), as famílias das águas do SAG na porção Centro-Norte do Estado do Paraná são as seguintes: bicarbonatada cálcica; bicarbonatada sódica; bicarbonatada cálcica com teor elevado de sódio; mista, sódica e sulfatada-cloretada sódica. Esse último tipo coincide com as águas analisadas na bacia Hidrográfica do Paraná 3.
É importante frisar que quando se menciona a influência das águas do SAG sobre as águas do SASG, não se descarta a possibilidade de que os elevados teores de ânions e de cátions serem provenientes de aquíf́eros subjacentes ao SAG. Bittencourt (1996) ao discutir os controles naturais do quimismo de águas termais na bacia do Paraná, mencionou a possibilidade de contaminação dos aqüíferos Botucatu e Pirambóia e Serra Geral por soluções originadas de formações paleozóicas sotopostas, conduzidas através de sistemas de fraturas.

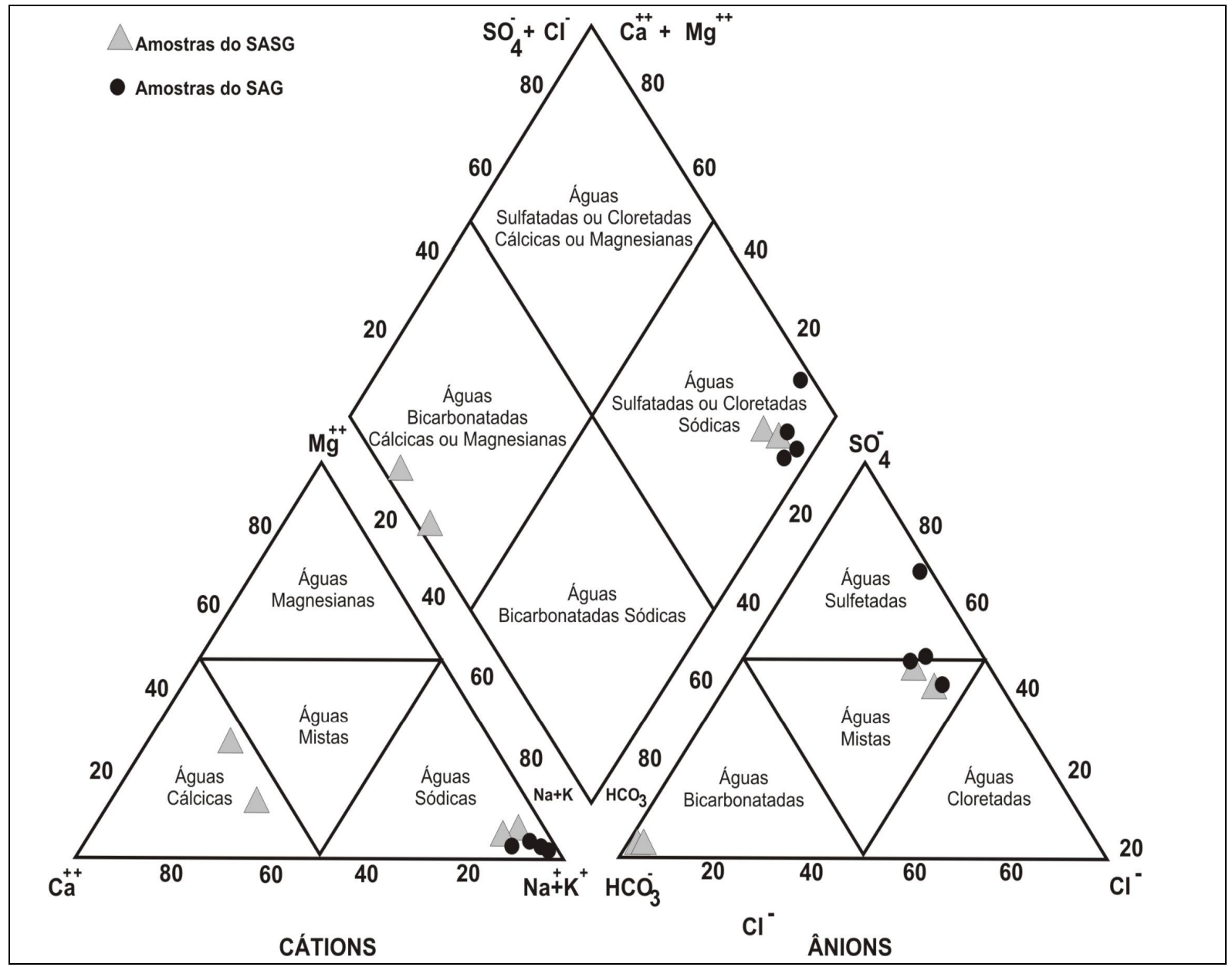

Figura 3- Diagrama de Piper de águas coletas em poços penetrantes no SASG e no SAG, na bacia hidrográfica do Paraná 3

Figure 3- Diagrama de Piper de águas coletas em poços penetrantes no SASG e no SAG, na bacia hidrográfica do Paraná 3 
Tabela 3- Análises físico-químicas das águas coletadas nos poços do SASG e do SAG na área da Bacia do Paraná 3

Table 3- Análises físico-químicas das águas coletadas nos poços do SASG e do SAG na área da Bacia do Paraná 3

\section{Água coletada em poços penetrantes no SAG}

\begin{tabular}{|c|c|c|c|c|c|c|c|c|c|c|c|c|c|}
\hline Cidade & $\frac{\pi}{2}$ & 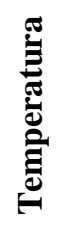 & 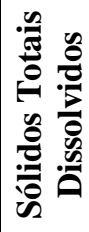 & 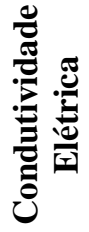 & 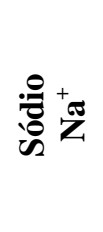 & 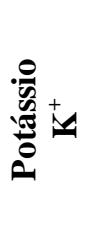 & ปึ & 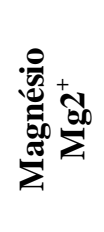 & Uं & 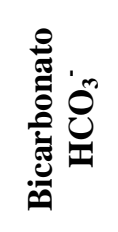 & ن́ & 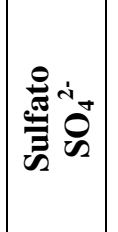 & 总 \\
\hline $\begin{array}{l}\text { Mal. Cândido } \\
\text { Rondon }\end{array}$ & 8,14 & 38 & 1650 & 3260 & 1280,0 & 7,6 & 111,40 & 12,40 & 612,00 & 61,63 & 0 & 2450,0 & 7,35 \\
\hline Itaipulândia & 8,50 & 41 & 2208 & 3570 & 756,0 & 4,3 & 12,80 & 2,90 & 448,00 & 228,90 & 4,70 & 840,5 & 5,40 \\
\hline $\begin{array}{l}\text { Foz do Iguaçu } \\
\text { (M.H.) }\end{array}$ & 8,26 & 39 & 2051 & 4980 & 712,0 & 6,3 & 28,11 & 11,04 & 491,70 & 209,60 & 0 & 654,0 & 8,50 \\
\hline $\begin{array}{l}\text { Foz do Iguaçu } \\
\text { (B.H.) }\end{array}$ & 8,70 & 40 & 2117 & 4430 & 750,0 & 1,7 & 22,80 & 9,63 & 482,48 & 202,12 & 11,74 & 694,6 & 6,90 \\
\hline VMP** & - & - & 1000 & - & 200 & - & - & - & 250 & - & - & 250 & 1,5 \\
\hline
\end{tabular}

Água coletada em poços penetrantes no SASG

\begin{tabular}{|c|c|c|c|c|c|c|c|c|c|c|c|c|c|}
\hline Cidade & $\frac{\pi}{2}$ & 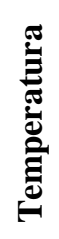 & 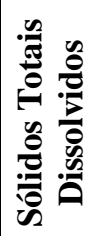 & 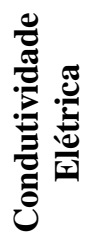 & 递尔 & 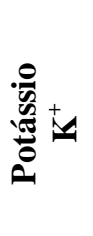 & J゙ & 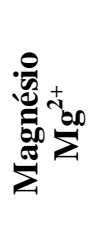 & Uं & 疍 & نُ & 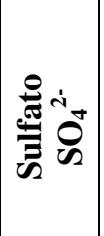 & 总 \\
\hline $\begin{array}{l}\text { Mal. Cândido } \\
\text { Rondon }\end{array}$ & 7,89 & 26 & 176 & 228 & 15,6 & 0,5 & 26,24 & 3,38 & 0,60 & 131,21 & 0 & 0,5 & 0,09 \\
\hline Itaipulândia* & 7,63 & 28 & 161 & 200 & 7,8 & 0,7 & 22,94 & 7,05 & 1,15 & 110,80 & 0 & 0,5 & 0,11 \\
\hline $\begin{array}{l}\text { Foz do Iguaçu } \\
\text { (M.H.)* }\end{array}$ & 8,65 & 33 & 1983 & 5004 & 646,0 & 6,4 & 31,52 & 8,87 & 482,00 & 247,30 & 5,45 & 636,2 & 8,20 \\
\hline Guaíra* & 7,20 & 31 & 1182 & 1906 & 400,0 & 2,7 & 42,77 & 9,67 & 265,46 & 116,58 & 0 & 347,4 & 5,40 \\
\hline VMP** & - & - & 1000 & - & 200 & - & - & - & 250 & - & - & 250 & 1,5 \\
\hline
\end{tabular}

Os valores dos parâmetros estão expressos em $\mathrm{mg} / \mathrm{L}$, exceto o $\mathrm{pH}$ e a condutividade elétrica $(\mu \mathrm{S} / \mathrm{cm})$

* Poços penetrantes no SASG, próximos de poço do SAG sem revestimento

** VMP = Valor Máximo Permitido, de acordo com a Portaria 518/2004 do Ministério da Saúde

Aproveitamento de águas do SAG impróprias para o consumo in natura

Uma das alternativas de aproveitamento de águas influenciadas pelo SAG, impróprias para o consumo humano in natura, em face de teores além dos permissíveis pelas normas, é a diluição com águas superficiais contendo baixos teores de matéria dissolvida. Como as variáveis químicas que frequientemente ultrapassam os valores máximos permissíveis (VMP) são os sólidos totais dissolvidos (STD), sódio $\left(\mathrm{Na}^{+}\right)$, cloreto
$\left(\mathrm{Cl}^{-}\right)$, sulfato $\left(\mathrm{SO}_{4}{ }^{2-}\right)$ e fluoreto $\left(\mathrm{F}^{-}\right)$, de início calcula-se os fatores de concentração da água a ser aproveitada em relação aos seus VMPs. Considere-se como fator de concentração o quociente entre o teor da variável na água que se quer aproveitar e o VMP, ou seja:

Fator de concentração $=$ concentração da variável na água / VMP (concentrações em mg/ $\mathrm{L}^{-1}$ )
(Eq. 1) 
Isto feito toma-se como referência o fator de concentração mais elevado, para o cálculo da diluição necessária com uma água com baixa concentração em material dissolvido, disponível no local.

A equação básica para cálculos de diluição, considerando-se um volume final unitário é:

$\mathrm{C}_{\text {final }}=\mathrm{C}_{\text {inicial }} \times \mathrm{Q}_{\text {inicial }}+\mathrm{C}_{\text {diluição }} \times \mathrm{Q}_{\text {diluição }}$

(Eq. 2)

onde:

$\mathrm{C}_{\text {final }}=$ Concentração final desejada, ou o Valor Máximo Permissível

$\mathrm{C}_{\text {inicial }}=$ Concentração da variável mais crítica na água a ser diluída

$\mathrm{Q}_{\text {inicial }}=$ Volume da água a ser diluída

$\mathrm{C}_{\text {diluição }}=$ Concentração da água de diluição

$\mathrm{Q}_{\text {diluição }}=$ Volume necessário da água de diluição

Tomando como exemplo a diluição da água do poço de Foz do Iguaçu (MH) com água do Dique Bela Vista (Tabela 3), são obtidos pela Eq. 1 os seguintes fatores de concentração:

$\mathrm{FC}_{\mathrm{STD}}=2,05 ; \mathrm{FC}_{\mathrm{Na}}=3,56 ; \mathrm{F}_{\mathrm{Cl}}{ }^{-}=1,97$;

$\mathrm{FC}_{\mathrm{SO}_{4}{ }^{2-}}=2,62$ e $\mathrm{FC}_{\mathrm{F}-}=5,67$

A maior diluição necessária corresponde ao íon floreto, que tem o maior fator de concentração, logo sua diluição ditará os volumes necessários para se obter uma água em condições de consumo pelas normas vigentes.

Aplicando-se a equação de diluição (Eq. 2)

$$
\begin{gathered}
1,5=8,5 * \mathrm{Q}_{\text {inicial }}+0,0 * \mathrm{Q}_{\text {diluição }} \\
\mathrm{Q}_{\text {inicial }}=0,1765
\end{gathered}
$$

e como

$$
\mathrm{Q}_{\text {inicial }}+\mathrm{Q}_{\text {diluição }}=1 \mathrm{~m}^{3} \text {, }
$$

então, cada metro cúbico de água apta para abastecimento deverá ter no máximo $17,65 \%$ de água relacionada ao SAG e $82,35 \%$ de água superficial. No caso do limite considerado for de $1,2 \mathrm{mg} / \mathrm{L}$, a proporção será de $14 \%$ de água do SAG para $86 \%$ de água de diluição sem flúor.

Para se ter uma idéia da composição da água após a mistura foi utilizado o programa computacional PHREEQEC (PARKHURST, 2007) que gera uma composição simulada, com base nas composições das frações misturadas e em valores das constantes de equilíbrio químico das reações envolvidas (Tabela 3 ).

\section{CONCLUSÕES}

As águas captadas de poços penetrantes no SAG, apontados na figura 1, são sulfatadas ou cloretadas sódicas, com teores de STD entre 1.650 a $2.208 \mathrm{mg} . \mathrm{L}^{-1}$ e temperaturas que variam entre 38 e $41^{\circ} \mathrm{C}$. Estando acima dos limites para o abastecimento público, in natura, essas águas podem ser diluídas com base nas composições das frações misturadas com constates de equilíbrio químico, e a partir disto disponibilizadas para o consumo humano. Os poços que seccionam apenas os basaltos, com profundidades de até $180 \mathrm{~m}$, sofrem influência das águas do SAG, ora indicadas por temperaturas de até $28^{\circ} \mathrm{C}$ e, nos casos mais nítidos, pela similaridade com as características físicas e químicas das águas de aqüíferos subjacentes.

Não existe continuidade do SAG na região da bacia do Paraná 3. Os falhamentos geológicos estão delineados pelos rios Ocoi e São Francisco Falso. Estas estruturas obedecem aos mesmos padrões dos alinhamentos dos rios Iguaçu, Piquiri, Alonso e de São Jerônimo-Curiuva, sendo que os rejeitos de blocos, nessa zona, atingem valores acima de $300 \mathrm{~m}$.

\section{AGRADECIMENTOS}

Os autores agradecem a Itaipu Binacional pelos recursos financeiros cedidos à pesquisa, sem os quais não teria sido possível desenvolver este trabalho, inclusive subsidiando as dissertações de Mestrado em Geologia da UFPR de Gustavo Barbosa Athayde e de Alexander Bittencourt. Especial agradecimento é feito a Simone Frederigi Benassi, Bióloga de Itaipu, pela cessão de informações e constante atenção que ela dispensou aos pós-graduandos acima mencionados.

Agradecem igualmente aos geólogos João Horácio Pereira, da SANEPAR, Mário Kondo e Jurandir Boz Filho, da SUDERHSA Superintendência de Recursos Hídricos e Saneamento Ambiental, pelo fornecimento de dados referentes aos poços existentes na área de estudo. 


\section{REFERÊNCIAS}

BITTENCOURT, A.V.L. Sólidos hidrotransportados na bacia hidrográfica do Rio Ivaí: Aplicação de balanços hidrogeoquímicos na compreensão da evolução de processos da dinâmica externa. 1978. 201p. Tese (Doutorado) - USP, São Paulo, 1978.

BITTENCOURT, A.V.L; ROSA FILHO, E.F.; HINDI E.C. BUCHMANN FILHO, A.C. A influência dos Basaltos e de misturas com águas de aqüíferos sotopostos nas águas subterrâneas do sistema aquífero Serra Geral na bacia do rio Piquiri, Paraná - BR, Águas Subterrâneas, v.17. p.67-75. 2003.

BORGHETTI. N.R.B; BORGHETTI. J.R; ROSA FILHO, E.F. Aquíffero Guarani - A verdadeira Integração dos Países do Mercosul. Curitiba, 214p. 2004.

CAETANO-CHANG, M.R.; WU, F.T. Bacia do Paraná: Formações Pirambóia e Botucatu. In: CONGRESSO BRASILEIRO DE GEOLOGIA, 37., 1992, São Paulo. Roteiro de Excursão, São Paulo: SBG. 1992. 19p.

CAMPOS, L.F.G. Secção geológica. In: COMMISSÃO GEOGRAPHICA E GEOLOGICA DA PROVÍNCIA DE SÃO PAULO. Relatório 1889. São Paulo. p.21-34. Anexos. 1889.

CELliGOI, A; DUARTE, U. Aspectos Hidrogeoquímicos da Formação Serra Geral em Londrina (PR) In: CONGRESSO BRASILEIRO DE ÁGUAS SUBTERRÂNEAS, 8., 1994, Recife. Anais... Recife: ABAS, 1994. p.425-433.

CHANG, H.K.; KOWSMANN, R.O. Significado dos diques do arco de Ponta Grossa na abertura diferencial do atlântico sul., In: SIMPÓSIO NACIONAL DE ESTUDOS TECTÔNICOS, 3., 1991, Rio Claro. Boletim de Resumos, Rio Claro: SBG, 1991. p.77-78. DERBY, O.A; A Geologia da Região diamantífera da Província do Paraná. Arquivos do Museu Nacional do Rio de Janeiro. v.3, p.89-98. 1878.

FERREIRA, F.J.F. Alinhamentos estruturais magnéticos da região centro oriental da Bacia do Paraná - reavaliação da potencialidade e prospectividade em hidrocarbonetos. CONSÓRCIO CESP-IPT, p.144-166. 1982.

GORDON JÚNIOR, M. Classificação das formações gondwanicas do Paraná, Santa Catarina e Rio Grande do Sul. DNPM/DGM. Notas preliminares e estudos, Rio de janeiro, n.38, 20p. 1947.

HINDI, E.C. Hidroquímica e hidrotermalismo do Sistema Aquíf́ero Guarani no Estado do Paraná. 2007. 156p. Tese (Doutorado em Geologia Ambiental) - Departamento de Geologia, Universidade Federal do Paraná, Curitiba, 2007.

LEINZ, V. Contribuição a geologia dos derrames basálticos ao sul do Brasil. Boletim da Faculade de Filosofia, Ciências e Letras. Geologia, São Paulo, n.5, p.1-103. 1949.
MEZZALIRA, S. (ORG.) Léxico estratigráfico do Estado de São Paulo. Boletim do Instituto Geológico, São Paulo, v.5, 161p. 1981.

PARAGUASSU, A.B. Contribuição ao estudo da Formação Botucatu: sedimentos aquosos, estruturas sedimentares e silicificação. 1968. 131p. Tese (Doutorado) apresentada a Escola de Engenharia de São Carlos/USP, São Carlos, 1968.

PARKHURST, .A. PHREEQEC. Disponível em: $<$ (http://wwwbrr.cr.usgs.gov/projects/GWC_coupled/p hreeqec/) > Acesso em: 2006.

PACHECO, J.C. Relatório elucidativo do esboço geológico da região compreendida entre o meridiano 4 Rio Itararé e os $23^{\circ} 34^{\prime}$ e $24^{\circ} 38^{\prime}$. In: COMMISSÃO GEOGRAPHICA E GEOLOGICA DO ESTADO DE SÃO PAULO. Exploração da região compreendida pelas folhas topográficas de Sorocaba, Itapetininga, Bury, Itaporanga, Sete Barras , Capão Bonito, Robei. São Paulo. p. 9-12. 1927.

PICCIRILLO, E.M; MELFI, A J; The Mesozoic flood volcanism of the Paraná Basin: Petrogenic and Geophysical Aspects. São Paulo: IAG/USP. 600p. 1988.

PORTELLA FILHO C.V. Conexão hidráulica entre os Aquíferos Serra Geral e Guarani na região de Londrina - Maringá - PR, com base em dados aeromagnetométricos e hidroquímicos. 2002. 128 p. Dissertação (Mestrado) - Departamento de Geologia, Universidade Federal do Paraná, Curitiba, 2002.

ROSA FILHO, E.F.; SALAMUNI, R.; BITTENCOURT, A.V.L. Contribuição ao estudo das águas subterrâneas nos basaltos no Estado do Paraná. Boletim Paranaense de Geociências, n.37. p.22-52, 1987

ROSA FILHO, E.F.; HINDI, E.C; GIUSTI, D.A; NADAL C.A; MONTOVANI, L.E. Usos potenciais do hidrotermalismo do Sistema Aquífero Guarani. Boletim Paranaense de Geociências, v.48, p.63-69. 2000

ROSA FILHO, E.F.; HINDI, E.C; BITTENCOURT, A.V.L; ARAVENA R; Caracterização Hidroquímica do Aqüífero Guarani na porção centro-norte do Estado do Paraná, Brasil. Águas Subterrâneas, Curitiba, v.19 n.1, p87-94, 2005.

ROSA FILHO, E.F.; HINDI, E.C.; DUARTE, U.; XAVIER, J.M. Estudo do movimento das águas subterrâneas do sistema Aquiífero Guarani (SAG) através de isótopos, no Paraná, São Paulo e no Uruguai. Organização dos Estados Americanos (OEA), Fundo Acadêmico. Disponível em: <http://w.w.w.sg-guarani.org> Acesso em: 2006.

RUEGG, N.A. Modelos de variações químicas na província basáltica do Brasil meridional: Característica do teor, distribuição geográfica e diferenciação, 1975. Tese (Livre Docência)IGC/USP, São Paulo, 1975. 
SARTORI, P.L.P; MACIEL FILHO, C.L; Petrologia da sequiência vulcânica da Formação Serra Geral no rebordo ocidental do planalto meridional (RS), In: CONGRESSO BRASILEIRO DE GEOLOGIA, 19., 1976. Anais... SBG 1976. v.1

SARTORI, P.L.P; GOMES, C.B; Composição química mineralógica das últimas manifestações vulcânicas na região de Santa Maria (RS). Anais da Academia Brasileira de Ciências, Rio de Janeiro, v.52(1), p.125-133. 1980.

SCHNEIDER, R.L.; MÜHLMANN, H.; TOMMASI, R.A.; MEDEIROS, R.A.; DAEMON, R.F.; NOGUEIRA, A.A. Revisão estratigráfica da Bacia do Paraná. In: CONGRESSO BRASILEIRO DE GEOLOGIA, 28,. 1974, Porto Alegre. .Anais... Porto Alegre: SBG, 1974, v.1, p.41-65.

SOARES, P.C. O Mesozóico Gonduânico no Estado de São Paulo. 1973, 152p. Tese (Doutorado)Departamento de Geologia e Mineralogia da Faculdade de Filosofia, Ciências e Letras, Universidade Estadual Paulista, Rio Claro, 1973.

SOARES, P.C. Divisão estratigráfica do Mesozóico no Estado de São Paulo. Revista Brasileira de Geociências, São Paulo, v.5(4), p.229-251, 1975.

SOUZA, A.A. Caracterização da bacia do rio Iguaçu a jusante do Município de Reserva do Iguaçu, como área de descarga do Aqüífero Guarani. 2004. 51p. Dissertação (Mestrado)Departamento de Geologia, Universidade Federal do Paraná, Curitiba, 2004.
STRUGALE, M. Arcabouço e Evolução estrutural do arco de Ponta Grossa no Grupo São Bento (Mesozóico): implicações na hidrodinâmica do Sistema Aqüífero Guarani e na migração de hidrocarbonetos na bacia do Paraná. 2002. 124p. Dissertação (Mestrado) - Departamento de Geologia, Universidade Federal do Paraná, Curitiba, 2002.

ZALÁN, P.V.; CONCEIÇÃO, J.C.J.; ASTOLFI, M.A.M.; APPI, V.T.; WOLFF, S.; VIEIRA, I.S.;MARQUES, A. Estilos estruturais relacionados a intrusões magmáticas básicas em rochas sedimentares. Boletim Técnico da Petrobrás, v.28, p.221-230. 1985.

WHITE, I.C. Relatório final da comissão de estudos das minas de carvão de pedra do Brasil. Rio de Janeiro. 1908.

WU, F.T.; CAETANO-CHANG, M.R. Estudo mineralógico dos arenitos das formações Pirambóia e Botucatu no centro-leste do Estado de São Paulo. Revista do Instituto Geológico do Estado de São Paulo, São Paulo, v.13, p.58-68, 1992. 